\title{
Social Status and Public Spaces
}

\author{
Gazmend Abrashi, PhD.c
}

\section{Doi:10.5901/ajis.2015.v4n3s1p426}

\begin{abstract}
Achievements and perfection of digital communications have brought us new challenges regrding to how we can and should use this communication, until to which limits it has to be used. From this starting point can reach up to the issue of public space, up to her what we mean by public space, public space intellectual understanding, which is a product of the human minds. However, for many media scholars and theorists of social sciences, the theory of Jurgen Habermas's public sphere may seem that early aging. In his famous study, Structural Transformation (1989/1962), Habermas builds his model on the development of bourgeois society of 17th century dh 18th in Europe. Based on this context, it suggests the formation of a space, which was conducted primarily between the economy and the states, where people can be infored and be able to discuss, in order to come up with decisions and act on those decisions.
\end{abstract}

Keywords: social, status, public, spaces, communications, challenges, intellectual, media, products, human.

\section{Theoretical Framework}

Making a review of the flow of events intellectual activity the human, in terms of time, first of all we had the script, then the development of the press (the press means all sorts of publications, including the types of publications in this century) The next most important development in the process of development of communication is digital communication, which has broken the barriers that existed, using two earlier developments in the field of communications. Arrival and përsoshmëria digital communication has brought us new challenges to how we can and should use this way of communication, to which limits should use it, what are the positive and which are negative? From this we come to the issue of public space, up to her what we mean by public space that surrounds us, understood the intellectual public space I publicity which is a product of the human mind. No doubt that the development of media on the surface strongly with the public, it aimed at all agency-factors and so itself as konglamerat represents an agency-factor unstructured. But be given that long, even first had an approach, which supported by Habermas that the public by a social category historical, dictated by these dynamic processes, developed in public opinion that represents, in fact, a political-philosophical categories. ${ }^{1}$

For Habermas, bourgeois public sphere was basically formed by the values of the elite dialogue. Printed in major magazines, oriented in the form of dialogue or rather in the form of editorial. However, many media scholars and political scientists, the theory of Jurgen Habermas's public sphere may seem at the beginning of aging, when one considers the landscape of television in Europe or elsewhere. In his famous study, the structural transformation of the public sphere (1989/1962), Habermas builds his model of bourgeois society on the development of 17th-century and 18th in Europe. Based on this context, it suggests that a space was formed afterwards and realized between the economy and the states, where people can be informed and discuss, in order to form decisions and act on those decisions.

The instruments of this area were: newspapers, books, salons and societies where debate on a relatively unique arena eg Church and State or, characterized by openness to all citizens. Forum also sees such a communication as a model for a public sphere that facilitates rational-critical debate among citizens, which accordingly ensures the formation of political will, and therefore it is essential for democracy.

To have a public space for better quality and which recognizes and protects the issues raised in the general interest needs against public officials who have a relationship contradictory in general, trying to be out of the vicious circle with the aim of protecting, preserving, education and development of their views, both types have a common public, and that is the issue or rather which measures problems such as issues of general interest. But, in reality against public 
capacity it is very small, not to say very small electronic media. ${ }^{2}$

The importance of the idea of Habermas's public sphere, one can say that had more significance and echoes her to sensitize the public on this issue. Only very large number of reviews and criticism emphasizes the importance of this opinion. Different points of dissatisfaction include a requirement that Habermas idealizes the bourgeois public sphere and favors for public enlightenment while neglecting others. Yet another criticism is that rational consensus Habermas highlights the continuing need and not to compromise the different interests and a pluralistic public sphere. He rejects the traffic that is not directed towards consensus and accordingly creates a very large boundary between information and entertainment.

However, the analysis of the substance of the case, we should stop to it than what is public and what is private, what is the boundary between these two notions. So, both public and private are the essence of what we discuss taking the idea of the public sphere, namely the difference or opposition between public and private. This theory is widely debated in political and social sciences (eg, Dahlgren discussions in 1995 and 2005). Only public and private settings are complex: for example, John B. Thompson (1995, 121-123) identified two different meanings for public and private attributes that both have been important in discussions about media. The first meaning relates to the private sphere, composed of organizations operating in a market economy and personal life and relations among them; and public property including economic and other organizations state. Between these two poles there are, according to him, the intermediate organizations such as political parties. On the other hand, Thompson sees another meaning to the concepts of public and private that their meanings are taken as attributes (public, private): These are related to visibility and invisibility, publicity and privacy. ${ }^{3}$

This understanding has been widely discussed in relation to the media, both scientists as they study the political and cultural rights in relation to the media, it appears that opinions on these attributes are very fast and constantly under change of opinions (an account summary discussion is provided by, for example, Dahlgren, 2005, 419). Often used empirical examples such as "celebrity status and their affairs private," "popular media", "ordinary people", these statements more clearly show that this issue is sensitive and affects us all, pavarërsisht whether we are or are not public profile people, of course, public profile people, are attacked in the context of the confrontation and the publication of personal items without their will and consciousness. ${ }^{4}$

However, the question arises whether there is a private man, in the sense that despite the exercise of public profile, can have personal life separate from her public presentation. In most Western democracies, discussions are geared to redefine public and private, the problem is posed in such a way that gjithënjë growing interest to get as much of it private, so, from another's privacy, can be overshadowed and make invisible all the issues that have special importance for society at large. One of the frequently cited works in terms of political communication which provides the crisis of public communication is what the authors Blumler \& Gurevitch 1995.

Some authors have claimed also that kind of policy-making has its own importance in the creation and conception of the public sphere, and as a starting point have had this type of policy, as in the private but also in everyday life; and that such policies are well fed, if only because of popular culture which evokes official resistance against hegemony or "power-blocks" for example to Fiske 1989, which brilliantly elaborates the development of this issue. If either of these views is correct it is a question, but they stress the idea that Habermas's public sphere, needs further consideration in the definition of what is intended and desired to the public.

Regarding the need for updating of this issue, the notions of public and private are regarded as notions more specifically, made by many scholars in the 1990s, that Habermas remains insensitive to the dynamics of development between the two genders or even wars other social groups. This way of thinking finds ground as critical theory and cultural studies. Notably, feminist theorists issues such as Nancy Fraser (eg, 1991) and media researchers as Lisa McLaughlin (1998) and Annabelle Sreberny-Mohammadi and Liesbet van Zoonen (1999) have emphasized the patriarchal-bourgeois nature the public sphere, which excludes women from the fields of their participation in civic life. This is certainly true of many other social groups and different movement, and this is why Habermas has been accused of elitism.

However, the ideals of the public sphere are present, for example, in many aspects of the law on the transmitter public, such as the ideals of free access to all citizens, and similar aspects that have to do with the fact that all the

\footnotetext{
${ }^{2}$ Coleman Stephen dhe Ross Karen, "The Media and the Public "Them" and "Us" in Media Discourse", fq.73.

${ }^{3}$ Mc Gannon, Donald, Communication research center, Bronx, fq. 6

${ }^{4}$ Mc Gannon, Donald, Communication research center, Bronx, fq.6.
} 
civilians They have the right to be informed by the public broadcaster, without making distinctions of ethnicity, religion or nationality. This discussion, which is naturally the claims of the crisis of public communication very well argue Blumlet and Gurevitch in publishing their 1995, which include the relationship aggressive public and tyranny of the media, and the decline of journalism - that threatens many liberal democracy .

"Habermas reflects the ambivalence which is felt more in terms of mass communication, but can be used for the public good? We suggest that pessimistic responses tend to underestimate the complex and contradictory nature or fragmented contemporary mass media, which paves the way for an escape from the institutional control, while more optimistic positions often ideally placed very high on the public sphere. These formulations alternative public sphere that receive and are built by nature complex and fragmented media, suggest a more positive than the media can facilitate and legitimize the debate of general public - through compromise and no consensus - and understanding between groups and marginalized opposition. ${ }^{5}$

Political actors can participate in an exchange of open and honest opinion. This applies to both types of policy, and creative life. Talk about the case when thinking about an issue formed an opinion about it, he sets out to others and try to convince you that your view, there is something in itself. At the same time they heard others say, that, if their arguments are better, to change opinion. This is a behavior related to politics. It is common to hear, and easy to believe that politics has little to do, or not at all, with calm and serious discussion. But here, more than anywhere, you must stay vigilant to distinguish reality from the sayings and images to. Democracy is not only elections and tërhepje rope. It is also a system that makes the debate a daily occurrence. Although participants did not always stand for rhetoric and analytical skills, it is impossible for them to contain the question: "why do you think so". 6

\section{Objectives}

Through certain research methodology arrives to collect information that will help us to respond to questions on research and testing of the hypothesis raised. This paper has used purely secondary research. So, secondary data are used to understand the problem posed. As secondary data are used literature various international and national. Through secondary data efforts have been made to be tested, respectively accepted or rejected the hypothesis of the paper, that social status is a precondition to enter the public space and social status, is a prerequisite to be part of the public space?

\section{Results}

Although it was planned and conducted in conditions and circumstances most closed as bourgeois salons and palaces, public spaces in the last century has undergone a major change in the way of creating debates, the way of confrontation of different actors. Now all are part of it regardless of social status which they enjoy, and can konstibuojnë differently in this public space.

The importance of the idea of the public sphere of Habermas, one can say that had more significance and echoes her to sensitize the public on this issue. Only very large number of reviews and criticisms highlights the importance of this opinion. Different points of dissatisfaction include a requirement that Habermas idealizes the bourgeois public sphere and public enlightenment favors for neglecting the others. Yet another criticism is that rational consensus Habermas highlights the continuing need and not to compromise the different interests and a pluralistic public sphere. He rejects the traffic that is not directed towards consensus and accordingly creates a very large boundary between information and entertainment.

Some authors have claimed also that kind of policy-making has its own importance in the creation and conception of the public sphere, and a start had this type of policy, as in the private but also in everyday life; and that such policies are well fed, if only because of popular culture which raise official resistance against hegemony or "power-blocks" for example to Fiske 1989, which brilliantly elaborates the development of this issue. If either of these views is correct it is a question, but they stress the idea that the public sphere of Habermas, needs further consideration in the definition of what is intended and desired to the public.

The development of mass media, market liberalization of the media, strengthening the new media like the Internet where among his many traditional media have opened web sites / portals and may have readers from all over the world, has created nessesary that almost most of their program to be commercially and not neutral and outside professional

\footnotetext{
${ }^{5}$ Mc Gannon, Donald, Communication research center, Bronx, fq.6.
}

${ }^{6}$ Malnes, Raino, Midgaard, Knut; "Filozofia politike", Rozafa, 2007, fq.9. 
ethics. To have as much public attention sensational information should be established to create this information, in most cases need to intervene in the private lives of public people. Using their private lives, we expect to publicity, which turns into trade and create such opinion and work in order to bring as many viewers to have as much advertising in their media.

Habermas separated as Marx, as well as by Weber, retaining only part of their critique of modernity. Human acts include all levels, without having to split them. Public space is not reserved on only institutional actors, but understood already being launched by civil society and the media of the measure (law and democracy, 1992) where distinguished associations and social movements, considered as major contributors to an arena that should constantly nourished.

$\mathrm{XVII}$ th century, it can not be considered as an idle period preceding the democratic prosperity, but he was moved by conflicting exchanges expressed in the literary sphere, unable expression in politics (Helen Merlin, 1994). Sociologists and historians dekristanizimit, especially Michel de Certeau (1975), it had clearly stated that religious beliefs were suppressed diversity of opinions and had allowed them to express themselves with the game's endless internal quarrels and deviations outside then. During the twentieth century's, in some East European countries that were under the tutelage communist Catholic Church it became a refuge contradictions, while Islam under his project unitary capture policy, hides diversity and tensions of public space including the feminine, according to researchers Nilufer Gole in 1997.

Public space thesis summarizes least two debates. First, the debate on how the rationality of actors: a guided them from logical reasons, in terms Habersian, or by interests and passions, with all that this entails strategic? This tension first, illuminating because it is based on the existence of different ways of expression, there is only reference to the scheme "idealists against sophists" should not forget that he can not serve to substancializuar reason and conviction as two units completely autonomous, rational or even right better rationalize power is just an act, viz. affects language that has achieved success as an effect language has its reasons, its rationale (in this regard, to follow the theory of generalized arguments of George Vignaux, 1976, that the justification as a decoration common all forms of recognition).

\section{References}

Berisha, Ibrahim; "Media: Agjensët e komunikimeve", Dukagjini, Prishtinë, 2006.

Mc Gannon, Donald, Communication research center, Bronx.

Goode, Luke, "Jurgen Habermas: democracy and the public sphere", 2005.

Malnes, Raino; Midgaard, Knut; "Filozofia Politike", Rozafa, Prishtinë, 2007.

Coleman Stephen dhe Ross Karen; "The media and the public "Them" and "Us" in Media Discourse. 